\title{
APPLICATION OF THE CONSERVATIVE AVERAGING FOR THE FILTRATION PROBLEM WITH LARGE VELOCITY
}

\section{J. JEGOROV, A. BUIKIS}

University of Latvia, Institute of Mathematics, Latvian Academy of Sciences Akadēmijas laukums 1, LV-1524, Rīga, Latvia

E-mail: buikis@latnet.lv, jegorovs@mathematik.uni-kl.de

Received September 22, 2001; revised November 13, 2001

\begin{abstract}
In this paper we consider a filtration problem in a rectangle or a perturbed rectangle region with an essential nonlinearity and high values of velocity. The conservative averaging method with quadratic or rational approximation over the rectangle thickness gives us 1D problem instead of the original 2D problem. This 1D solution can be used as an initial approximation for the original $2 \mathrm{D}$ problem. The conservative averaging method is considered and results of some numerical experiments are presented.
\end{abstract}

\section{THE FORMULATION OF THE PROBLEM}

We consider the following differential equation inside the domain $\Omega \subset \mathbb{R}^{2}$ :

$$
-\operatorname{div}\left(F_{1}(\mathbf{x}, u) \mathbf{I} \cdot \operatorname{grad} u\right)=-\operatorname{div} F_{2}(\mathbf{x}, u),
$$

where $\mathbf{x}=(x, y)^{T}$ and $\mathbf{I}$ is the unitary matrix. Functions $F_{1}(\mathbf{x}, u)$ and $F_{2}(\mathbf{x}, u)$ can be expressed in the following form:

$$
\begin{aligned}
& F_{1}(\mathbf{x}, u)=\Theta \frac{f_{1}^{3}(\mathbf{x})}{1-f_{1}^{2}(\mathbf{x})} f_{2}^{3.5}(\mathbf{x}, u) \\
& F_{2}(\mathbf{x}, u)=\alpha f_{1}(\mathbf{x}) f_{2}(\mathbf{x}, u) f_{3}(\mathbf{x}),
\end{aligned}
$$


where $\Theta, \alpha \in \mathbb{R}$. The functions $f_{i}, i=1,2,3$ are given by

$$
\begin{aligned}
& f_{1}(\mathbf{x})= \begin{cases}\frac{3}{5}, & x<40 \text { or } x>60, \\
\frac{3}{1000} x^{2}-\frac{3}{10} x+\frac{39}{5}, & 40 \leq x \leq 60,\end{cases} \\
& f_{2}(\mathbf{x}, u)= \begin{cases}\frac{1}{\frac{1}{10}+\left(\frac{u}{-3000\left(f_{1}(\mathbf{x})-1\right)}\right)^{2}}+\frac{1}{10}, & u(\mathbf{x})<0, \\
1, & u(\mathbf{x}) \geq 0,\end{cases} \\
& f_{3}(\mathbf{x})= \begin{cases}(1000,0)^{T}, & x<40 \text { or } x>60, \\
(1000,10 x-500)^{T}, & 40 \leq x \leq 60 .\end{cases}
\end{aligned}
$$

Let us add the following boundary conditions to the differential equation

$$
\begin{gathered}
u(\mathbf{x})=-2000, \forall \mathbf{x} \in \Gamma_{1}, \\
n \cdot\left(F_{1}(\mathbf{x}, u) \mathbf{I} \cdot \operatorname{grad} u\right)=0, \forall \mathbf{x} \in \Gamma_{2}, \\
n \cdot\left(F_{1}(\mathbf{x}, u) \mathbf{I} \cdot \operatorname{grad} u\right)=n \cdot\left(\alpha f_{1}(\mathbf{x}) f_{2}(\mathbf{x}, u) f_{3}(\mathbf{x})\right), \forall \mathbf{x} \in \Gamma_{3},
\end{gathered}
$$

where $n$ is the outer normal vector and

$$
\begin{aligned}
& \Gamma_{1}=\overline{A G}, \quad \Gamma_{2}=\overline{C B} \\
& \Gamma_{3}=\overline{A B} \cup \overline{G F} \cup \overline{D C} \cup \overline{D E F} .
\end{aligned}
$$

Thus we have the differential equation (1.1) with the boundary conditions $(1.7 \mathrm{a}, 1.7 \mathrm{~b}, 1.7 \mathrm{c})$. Now let us describe the domain $\Omega$. Firstly, we assume $\Omega$ to be the rectangle (see Fig.1):

For each the point we have the following coordinates: $A(0,0), B(100,0), C(100,1), D(60,1), E(50,1), F(40,1), G(0,1)$.

The equation (1.1) describes the dehydration of the porous material containing water and air during the technological process. The process is considered to be stationary. It is described by a non-linear diffusion-convection equation. The parameter $\alpha$ describes the velocity of the porous material trough a calendar, and the parameter $\Theta$ describes the influence of diffusion.

\section{THE AVERAGING OF THE DIFFERENTIAL EQUATION}

First, we rewrite the differential equation (1.1) in the form:

$$
\frac{\partial}{\partial x}\left(F_{1}(\mathbf{x}, u) \frac{\partial u}{\partial x}\right)+\frac{\partial}{\partial y}\left(F_{1}(\mathbf{x}, u) \frac{\partial u}{\partial y}\right)=\frac{\partial F_{2 x}(\mathbf{x}, u)}{\partial x}+\frac{\partial F_{2 y}(\mathbf{x}, u)}{\partial y},
$$




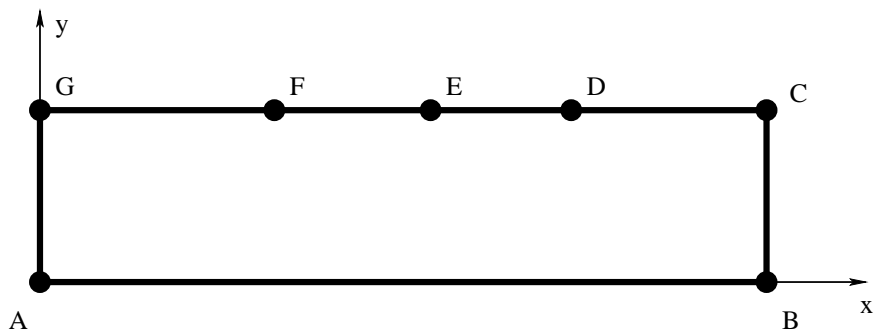

Figure 1. The rectangular domain $\Omega$.

where $F_{2 x}$ and $F_{2 y}$ are the components of the vectorial function $F_{2}$. Then we integrate the differential equation (2.1) in the direction of the y-coordinate:

$$
\begin{array}{r}
\int_{0}^{H}\left[\frac{\partial}{\partial x}\left(F_{1}(\mathbf{x}, u) \frac{\partial u}{\partial x}\right)+\frac{\partial}{\partial y}\left(F_{1}(\mathbf{x}, u) \frac{\partial u}{\partial y}\right)\right] d y= \\
\int_{0}^{H}\left[\frac{\partial F_{2 x}(\mathbf{x}, u)}{\partial x}+\frac{\partial F_{2 y}(\mathbf{x}, u)}{\partial y}\right] d y
\end{array}
$$

and introduce the function $v(x)$ in the form

$$
v(x)=\frac{1}{H} \int_{0}^{H} u(x, y) d y
$$

where $H$ is the thickness of $\Omega$ in the y-direction. In case of rectangle, we have $H=1$ (see Fig.1). Applying the function $v(x)$ to the differential equation (2.2) we obtain:

$$
\begin{gathered}
H \frac{\partial}{\partial x}\left(F_{1}(\mathbf{x}, v) \frac{\partial v}{\partial x}\right)+F_{1}(\mathbf{x}, v)\left(\left.\frac{\partial u}{\partial y}\right|_{y=H}-\left.\frac{\partial u}{\partial y}\right|_{y=0}\right) \\
=H \frac{\partial F_{2 x}(\mathbf{x}, v)}{\partial x}+\frac{\partial F_{2 y}(\mathbf{x}, v)}{\partial v}\left(\left.u\right|_{y=H}-\left.u\right|_{y=0}\right) .
\end{gathered}
$$

Here we assume that $F_{1}(\mathbf{x}, u) \sim F_{1}(\mathbf{x}, v)$ and $F_{2}(\mathbf{x}, u) \sim F_{2}(\mathbf{x}, v)$. Let us transform the equation (2.4) using boundary conditions (1.7):

$H \frac{\partial}{\partial x}\left(F_{1}(\mathbf{x}, v) \frac{\partial v}{\partial x}\right)+2 \varphi F_{1}(\mathbf{x}, v)=H \frac{\partial F_{2 x}(\mathbf{x}, v)}{\partial x}+\frac{\partial F_{2 y}(\mathbf{x}, v)}{\partial v}\left(\left.u\right|_{y=H}-\left.u\right|_{y=0}\right)$, 
where $\left.\frac{\partial u}{\partial y}\right|_{y=H}=\varphi,\left.\frac{\partial u}{\partial y}\right|_{y=0}=-\varphi$ and $\varphi=\frac{F_{2 y}}{F_{1}}$. Now we assume that the function $u(x, y)$ is dependent on the $\mathrm{y}$-coordinate as a parabolic function:

$$
u(x, y)=a(x)+b(x)\left(y-\frac{H}{2}\right)+c(x)\left(y-\frac{H}{2}\right)^{2} .
$$

Thus we can rewrite the equation (2.5):

$$
H \frac{\partial}{\partial x}\left(F_{1}(\mathbf{x}, v) \frac{\partial v}{\partial x}\right)+2 \varphi F_{1}(\mathbf{x}, v)=H \frac{\partial F_{2 x}(\mathbf{x}, v)}{\partial x}+\frac{\partial F_{2 y}(\mathbf{x}, v)}{\partial v} b(x) .
$$

In order to obtain an analytical expression for the function $u(x, y)$, the coefficients $a(x), b(x)$ and $c(x)$ have to be found. From the boundary condition (1.7c) we obtain

$$
\left\{\begin{array}{l}
\left.\frac{\partial u}{\partial y}\right|_{y=H}=b(x)+H c(x)=\varphi \\
\left.\frac{\partial u}{\partial y}\right|_{y=0}=b(x)-H c(x)=-\varphi
\end{array}\right.
$$

It means that $b(x)=0$ and $c(x)=\frac{\varphi(x)}{H}$ and the equation (2.7) can be written in the following form:

$$
H \frac{\partial}{\partial x}\left(F_{1}(\mathbf{x}, v) \frac{\partial v}{\partial x}\right)+2 \varphi F_{1}(\mathbf{x}, v)=H \frac{\partial F_{2 x}(\mathbf{x}, v)}{\partial x} .
$$

Thus we obtained the ordinary differential equation (2.9) with the boundary conditions (1.7a, 1.7b). Let us put (2.6) into (2.3) to find the coefficient $a(x)$, thus having $a(x)=v(x)-\frac{\varphi H}{12}$. Finally, we can write the expression for the function $u(x, y)$ :

$$
u(x, y)=v(x)-\frac{\varphi H}{12}+\frac{\varphi}{H}\left(y-\frac{H}{2}\right)^{2}
$$

The function $u(x, y)$ can be used as an approximation for the solution of differential equation (1.1).

Now we consider the case when the domain has the shape shown in Fig.2. Let us denote it $\Omega_{1}$. In this case the thickness of the domain in the y-direction depend on the x-coordinate, $H=H(x)$ (see Fig. 2). The geometry of this domain may make the averaging process for the equation (1.1) difficult because all the derivatives on the boundary are given in the direction of the outer normal vector. Though instead of $\frac{\partial u}{\partial n}$ we may take $\frac{\partial u}{\partial y}$, because the cosine of the angle between $\mathrm{y}$-axis and the normal vector for any $x$ is always nearly 1 (see Fig.3). Hence, we can assume $\frac{\partial u}{\partial n} \approx \frac{\partial u}{\partial y}$.

Now we can do the averaging for the differential equation (1.1) in similar way 


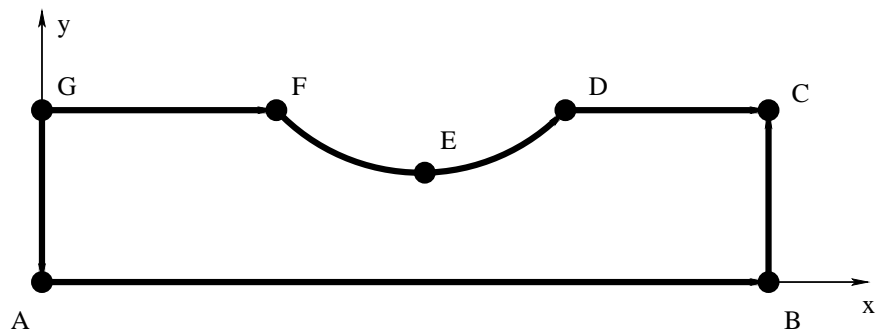

Figure 2. The perturbed rectangular domain $\Omega_{1}$, For each point we have the following coordinates: $A(0,0), B(100,0), C(100,1), D(60,1), E(50,0.5), F(40,1), G(0,1)$.

as earlier. We integrate the equation (2.1) in the y-direction from 0 to $H(x)$. We also introduce the function $v(x)$ in the form:

$$
v(x)=\frac{1}{H(x)} \int_{0}^{H(x)} u(x, y) d y .
$$

Finally, we obtain the following expression for the function $u(x, y)$ :

$$
u(x, y)=v(x)-\frac{\varphi H(x)}{12}+\frac{\varphi}{H(x)}\left(y-\frac{H(x)}{2}\right)^{2}
$$

and the following ordinary differential equation for $v(x)$ :

$$
H(x) \frac{\partial}{\partial x}\left(F_{1}(\mathbf{x}, v) \frac{\partial v}{\partial x}\right)+2 \varphi F_{1}(\mathbf{x}, v)=H(x) \frac{\partial F_{2 x}(\mathbf{x}, v)}{\partial x},
$$

where the function $\varphi$ is the same as in (2.5). The difference between formulae (2.12), (2.13) and (2.10), (2.9) is only in the value of the thickness in the y-direction.

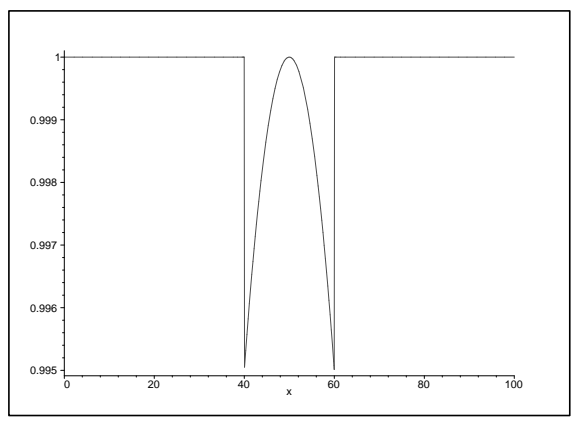

Figure 3. Cosine of angle between y-axis and normal vector, $\forall x$. 
For each of the considered domains $\left(\Omega\right.$ and $\Omega_{1}$ ) we did the conservative averaging of the differential equation (1.1). Now let us solve the ordinary differential equations (2.9) and (2.13) with the boundary conditions (1.7a, $1.7 \mathrm{~b})$. Both of them are discretisized by the monotone finite difference scheme as in [1]. The discrete problem is solved using the relaxation method with relaxation parameter $0<\omega<1$.

\section{NUMERICAL SOLUTIONS OF DIFFERENTIAL EQUA- TIONS (2.9), (2.13)}

During the numerical experiments, the following relations were observed. If the convection was dominant, i.e. $\Theta$ was not larger than $0.1 \alpha$, then for the space step $h=1$ the necessary amount of iterations was about 300 (see Fig.4); for the space step $h=0.25$ - around 200. It is visible that the reduction of the space step four times didn't change the form of the solution but cardinally influenced the numerical constant value on the right side (see Fig.5 and Fig.6).

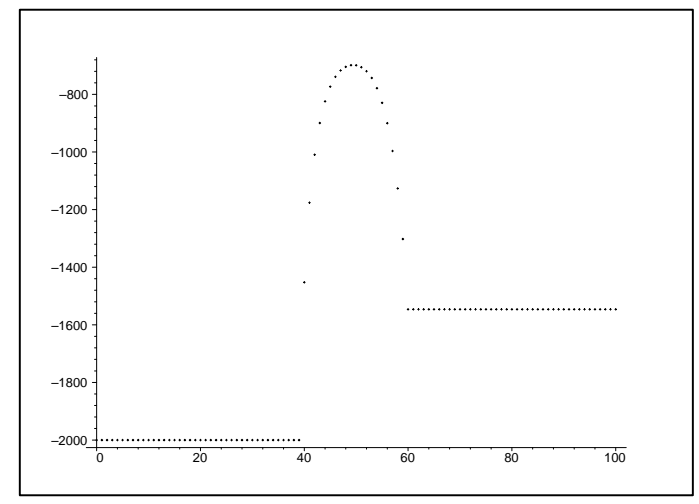

Figure 4. Numerical solution, $H=$ const, $\omega=0.075, h=1, \Theta=0.1, \alpha=1, k=400$.

The results obtained in the changing thickness of the domain $\mathrm{H}(\mathrm{x})$ are the same by the form, only the maximum value of the peak is changing. It grows from about -700 to -550 in case of the space step $h=1$, and from -900 to -700 for the step $h=0.25$. In the case of large diffusion when $\Theta$ is nearly $10 \alpha$ the necessary amount of iterations grows about three times comparing to the case when $\Theta=0.1 \alpha$. The largest necessary amount of iterations is needed in the case when both the parameters are equal. Large diffusion qualitatively changes the solution on the left side of the figure, where the boundary condition of the 1st kind is given. It is easily explained by the homogeneous diffusion equation with constant coefficients, which solution in $1 \mathrm{D}$ case is a linear function. Though for the boundary condition of the 2nd kind the solution has to be constant. This situation is visible on the Fig.7. 


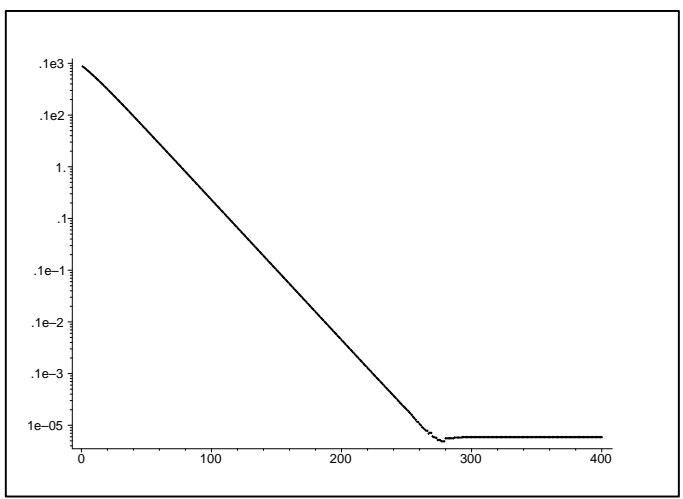

Figure 5. The discrepancy in the maximum norm, $H=$ const.

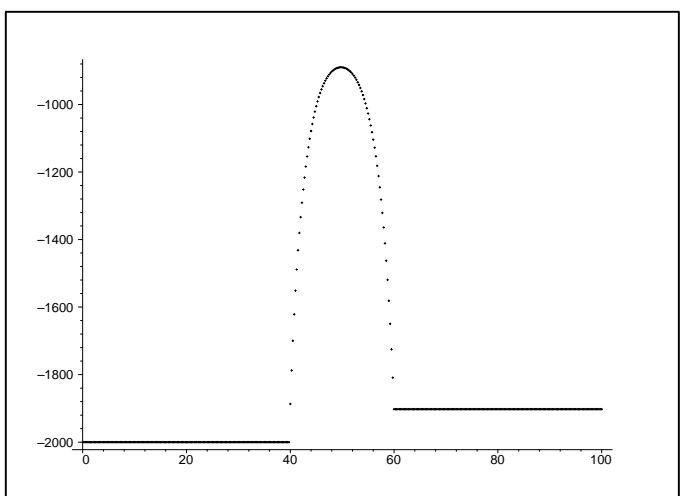

Figure 6. Numerical solution, $H=$ const, $\omega=0.075, h=0.25, \Theta=0.1, \alpha=1, k=300$.

The changes of discrepancy during the iteration process are non-monotonous, see Fig.8.

\section{THE CONSTRUCTION OF APPROXIMATION FOR 2D PROBLEM}

Let us construct the initial approximation for 2D problem. Renewing the 2D solution with the help of polynomial of 2nd order (see Fig.9), it is visible that around the principal points $\mathrm{x}=40$ and $\mathrm{x}=60$ solution has big jumps. The source of this phenomena is clear: in the place where calendar presses the material, the solution could have a boundary layer which cannot be reasonably approximated by a polynomial function. To avoid such a problem, let us use the rational spline, which is defined with the property of the conservative averaging, for the approximation in one interval (see the earlier publication 


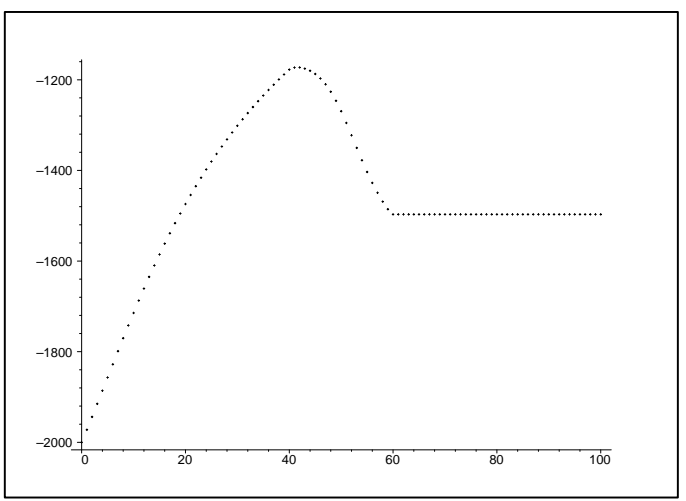

Figure 7. Numerical solution, $H=H(x), \omega=0.075, h=1, \Theta=100, \alpha=1, k=300$.

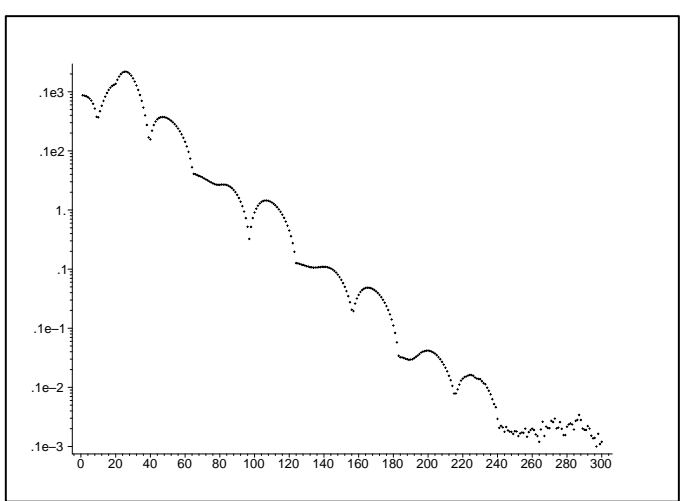

Figure 8. The discrepancy in the maximum norm, $H=H(x)$.

of one of authors [2]). We consider the following expression:

$u(x, y)=a(x)+b(x)\left(y-\frac{H(x)}{2}\right)+\frac{c(x)}{2}\left(\frac{y^{2}}{1+2 p(H(x)-y)}+\frac{(H(x)-y)^{2}}{1+2 q y}\right)$

where $p$ and $q$ are parameters. We apply the function (4.1) to the boundary conditions (1.7a, 1.7b, 1.7c), thus obtaining

$$
\left\{\begin{array}{l}
\left.\frac{\partial u}{\partial y}\right|_{y=H(x)}=b(x)+c(x)\left[H(x)+H^{2}(x) p\right]=\varphi \\
\left.\frac{\partial u}{\partial y}\right|_{y=0}=b(x)-c(x)\left[H(x)+H^{2}(x) q\right]=-\varphi
\end{array}\right.
$$




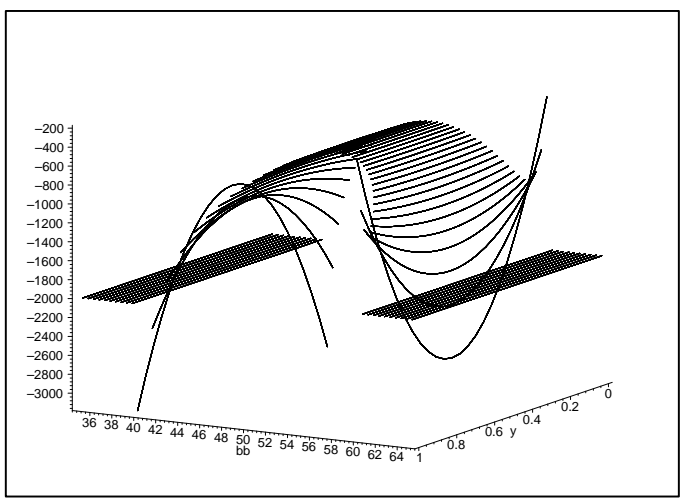

Figure 9. 2D approximation (polynomial function), $H=H(x)$.

Solving the system (4.2), we can find $b(x)$ and $c(x)$. Let us assume that $p=q$. In this case the coefficients $b(x)$ and $c(x)$ are

$$
\left\{\begin{array}{l}
b(x)=0 \\
c(x)=\frac{\varphi(x)}{H(x)(1+q H(x))}
\end{array} .\right.
$$

If we apply the expression (4.1) to the equation (2.11), then we obtain the coefficient $a(x)$ :

$$
a(x)=\frac{v(x)(1+H q)}{1+H q}-\frac{\varphi \ln (1+2 H q)\left(1+4 H q-4 H^{2} q^{2}\right)+6 H^{2} q^{2}+2 \varphi H q}{8 H^{2}(1+H q) q^{3}}
$$

Now we have all the coefficients and we can construct the function (4.1) without any problems for each positive $q$. The differential equation has the same form (2.9) or (2.13). It is visible that growing the value of the parameter $\mathrm{p}=\mathrm{q}$ we obtain the solution, which from one side has a boundary layer and from the other side doesn't have a jump. As the best value of the parameter $q$ we choose the minimal one when the maximum principle is fulfilled.

\section{CONCLUSION}

The method of conservative averaging allowed us to move from the $2 \mathrm{D}$ problem to the problem for one ordinary differential equation which can be solved by a monotone finite difference scheme. Using the approximation by a rational function we can obtain the approximate solution of the given $2 \mathrm{D}$ problem. Or it can be used as an initial 2D approximation, if we wish to solve more accurately the problem $(1.1)-(1.7 \mathrm{c})$. 


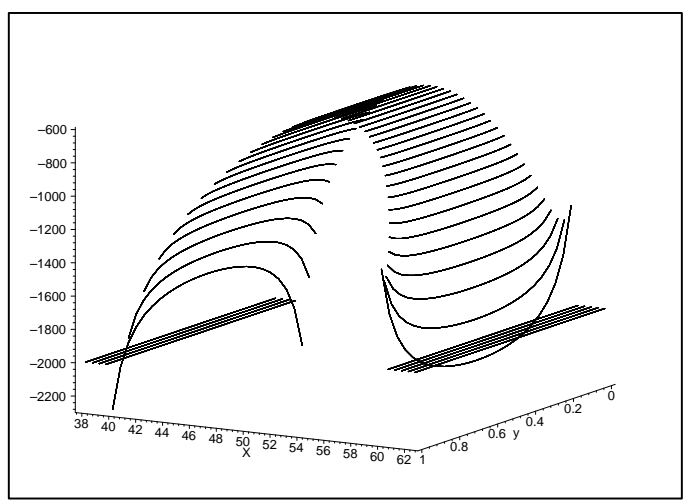

Figure 10. 2D approximation (rational function), $H=H(x), q=5$.

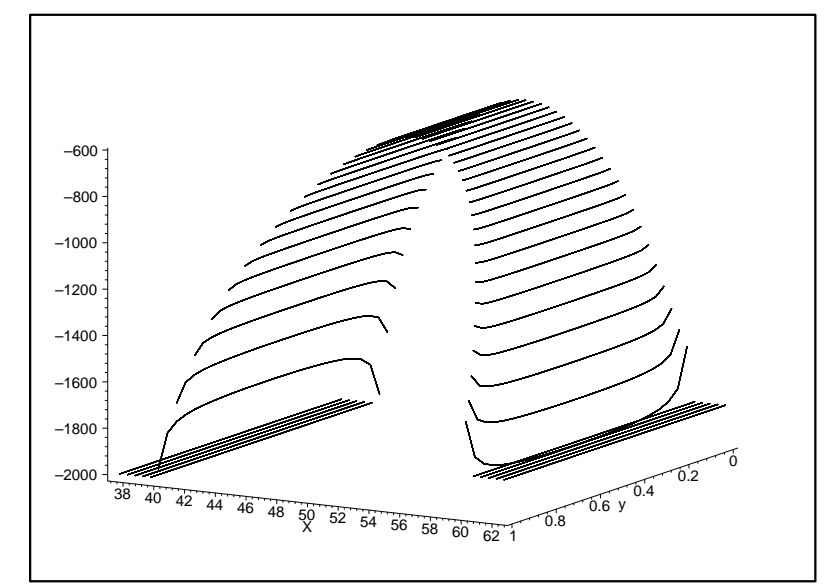

Figure 11. 2D approximation (rational function), $H=H(x), q=17$.

This work was supported partly by joint student's project "Flows in Layered Porous Media" of ITWM, Kaiserslautern, Germany and the University of Latvia, and partly by the grant 01.0130 of the Latvian Science Council.

\section{REFERENCES}

[1] H. Kalis. Numerical integration by finite-difference methods for some nonlinear problems. Mathematical Modelling. Applied Problems in Mathematical Physics. Proceedings of University of Latvia, $\mathbf{5 9 2}$ 1994, 73 - 90.

[2] A. Buikis. Rational splines that are interpolative in the mean and their properties. Latv. Math. Ezheg., 32 1988, 173 - 182.(in Russian)

[3] A. Buikis. Conservative spline - approximation for the differential equations with discon- 
tinuous coefficients. Numerical Analysis and Mathematical Modelling, Banach Center Publication, 24 1990, 487- 491.(in Russian)

Filtracijos uždavinio su dideliais greičiais sprendimas konservatyviu vidurkinimo metodu

J. Jegorov, A. Buikis

Straipsnyje sprendžiamas dvimatis filtracijos uždavinys. Sritis yra stačiakampè arba deformuota stačiakampè. Nagrinèjamas atvejis, kai skysčio tekejjimo greitis yra didelis ir būtina naudoti netiesinį matematinį modelį. Panaudojant vidurkinimo metodą $y$ koordinatès kryptimi sprendinys aproksimuojamas parabole, o lygtis yra vidurkinama. Gautoji vienmatè difuzijos-konvekcijos lygtis yra sprendžiama skaitiškai. Taip sudarytas sprendinys ne visada yra monotoniškas, todèl nagrinejjamas ir dar vienas artinys, kuris aprašomas racionalia trupmena. Pateikti skaičiavimo eksperimento rezultatai, gauti sprendžiant uždavinị dviem atvejais, kai vyrauja konvekcijos procesas arba difuzijos procesas. Algoritmo ir iteracinio proceso konvergavimas nèra ištirtas. 